\title{
Applications of new technology in molecular epidemiology and their relevance to occupational medicine
}

\author{
David Koh, Adeline Seow, Choon Nam Ong
}

\begin{abstract}
Technological advances in molecular biology over the past 2 decades have offered more complex techniques that can be used to study the role of specific exogenous agents and host variables that cause ill health. Increasingly, studies in human populations use this new technology, combined with epidemiological methods, to shed light on the understanding of the biological processes associated with development of disease. This approach has many potential applications in occupational and environmental medicine (OEM), and some aspects of the work in this growing field are reviewed. An understanding of biochemistry and genetics at the molecular level, specific knowledge on metabolism and mechanisms of action, and epidemiology have become increasingly important for the OEM practitioner. This is necessary to consider the major question of validation and relevance of these molecular biomarkers. As end users, OEM practitioners should also consider the impact of these advances on their practices. For example, the availability of genetic tests to identify susceptible workers raises issues of ethics, individual privacy, right to work, and the relevance of such tests. Several studies have presented data on the association of environmental measurements and various biomarkers for internal and biologically effective dose, genetic polymorphisms, and early response markers. Given the limitations of individual molecular biomarkers in assessing risk to health, and the multifactorial nature of environmental disease, it is likely that such an approach will increase our understanding of the complex issue of mechanisms of disease and further refine the process of risk assessment.

(Occup Environ Med 1999;56:725-729)
\end{abstract}

Keywords: molecular epidemiology; biomarkers; internal dose; biologically effective dose; early response markers; genetic polymorphisms

Dr D Koh, Department of Community, Occupational and Family Medicine, Faculty of Medicine, National University of Singapore, 16 Medical Drive, Singapore 117597, Republic

of Singapore. Telephone

0065 8744988; fax 0065

7791489; email

cofkohd@nus.edu.ss

Accepted 15 June 1999 studies in human populations use this new technology, combined with epidemiological methods, to shed light on our understanding of the biological processes associated with development of disease. This approach has many potential applications in occupational and environmental medicine (OEM), and we review here some aspects of the work in this growing field.

Molecular epidemiology, as this approach is commonly known today, was first made popular in relation to cancer research. ${ }^{12}$ It came into use in OEM in the middle to late 1980s. ${ }^{3}{ }^{4}$ The use of biological markers to monitor the health of the working population is itself not a new innovation, as clinicians and researchers have been using biochemical and cellular variables measured in human tissues and body fluids for many years. However, the availability of techniques to measure at the molecular levelfor example, structural gene damage, gene variation, and gene products in cells and body fluids - carried the promise of finding higher resolution answers ${ }^{5}$ to questions of cause in OEM.

The applications of molecular epidemiology in OEM can be described along two lines. Firstly, new technology improves our understanding of causality by allowing a more direct and accurate measure of exposure and outcome. ${ }^{56}$ The focus of environmental and occupational epidemiology is the study of causal relations between exposure to exogenous agents and the development of clinical disease. In epidemiology, measures of exposure are still often indirect: obtained by environmental monitoring, self report, or other surrogate measures-for example, hours of work. Measures of outcome also depend on the development of clinically detectable changes. The mechanism by which exposure leads to disease is often a mystery. This approach met with considerable success when exposure levels were high, and effects large, ${ }^{4}$ but often the greatest source of error was the potential for misclassification. With changing environments, more subtle exposures and smaller magnitudes of risk need to be elucidated. This has engendered the need for identification of early markers which will reflect the absorbed dose of a xenobiotic agent, a more accurate reflection of a person's exposure than ambient monitoring of the environment. ${ }^{7}$ The use of biological markers to better understand these pathways falls naturally into three categoriesmeasures of internal dose, early biological response, and host susceptibility (table). 
Examples of molecular biomarkers measued in OEM studies

\begin{tabular}{|c|c|c|c|}
\hline Molecular biomarkers & Application & Study population & Selected references \\
\hline $\begin{array}{l}\text { Exposure markers: } \\
\text { AFB1-DNA adduct }\end{array}$ & Food contamination and risk of liver cancer & General community & Groopman and Kensler, $1999^{6}$ \\
\hline PAH-DNA adduct & $\begin{array}{l}\text { Workplace and community exposures and } \\
\text { exposure to cigarette smoke, and risk of } \\
\text { lung cancer }\end{array}$ & $\begin{array}{l}\text { Foundry workers } \\
\text { Coke oven workers } \\
\text { General community in industrial areas }\end{array}$ & $\begin{array}{l}\text { Hemminki et al } 1997^{42} \\
\text { Pan et al } 1998^{47}\end{array}$ \\
\hline 4-ABP-haemoglobin adduct & Cigarette smoke and risk of bladder cancer & General community & Yu et al $1994^{33}$ \\
\hline $\begin{array}{l}\text { Early effect markers: } \\
\text { p53 tumour suppressor } \\
\text { gene or its protein product }\end{array}$ & $\begin{array}{l}\text { Specific fingerprint mutation in certain gene } \\
\text { codon and risk of liver, breast, lung, and } \\
\text { oesophageal cancer }\end{array}$ & $\begin{array}{l}\text { Radon exposed miners, vinyl chloride monomer } \\
\text { workers } \\
\text { General population with environmental exposure } \\
\text { to AFB1 }\end{array}$ & $\begin{array}{l}\text { Harris } 1993^{22} \\
\text { Smith et al } 1998^{24} \\
\text { Shen and Ong } 1996^{27}\end{array}$ \\
\hline $\begin{array}{l}\mathrm{H} \text {-ras and K-ras gene or its } \\
\text { protein product }\end{array}$ & $\begin{array}{l}\text { Increased risk of various cancers-for } \\
\text { example, lung, liver and bladder }\end{array}$ & $\begin{array}{l}\text { Firefighters, hazardous waste workers, foundry } \\
\text { workers, vinyl chloride monomer workers }\end{array}$ & $\begin{array}{l}\text { Brandt Rauf et al } 1989,1990^{19} 20 \\
\text { Luo et al } 1998^{18}\end{array}$ \\
\hline $\begin{array}{l}\text { Host susceptibility markers: } \\
\text { CYP1A1 polymorphism }\end{array}$ & $\begin{array}{l}\text { Increased risk of lung cancer with exposure } \\
\text { to benzo[a]pyrene }\end{array}$ & Foundry workers & Perera and Dickey $1997^{10}$ \\
\hline NAT2 polymorphism & Increased risk of bladder cancer & Workers exposed to arylamine and hydrazine & Ishibe and Kelsey $1997^{32}$ \\
\hline
\end{tabular}

Secondly, molecular epidemiology in occupational health enhances the process of quantitative risk assessment, ${ }^{8}$ and the extrapolating of results from animal studies to human populations $^{49}$ by providing more accurate dose-response data, and measurement of exposure. Individual susceptibility to the exposures in question can also theoretically be mapped by genetic studies. Information on the distribution of procarcinogenic changes or markers of susceptibility in groups of people also contribute to the characterisation in a population. ${ }^{10}$

\section{Markers of internal exposure}

Measures indicating internal exposure can be made at the level of total body burden, or at the target tissue. Measurement of the body burden of a xenobiotic agent or its metabolite is commonplace in OEM. For example, urinary 1-hydroxypyrene at the end of a shift has been used as a measure of internal dose for workers exposed to polycyclic aromatic hydrocarbons (PAHs), and this has been found to correlate well with total external exposure. ${ }^{11}$

An adduct is a complex that results when a chemical or its metabolite binds to biological material. DNA adducts, for example, are xenobiotic agents covalently bound to DNA. If left unrepaired, they may lead to gene mutation or neoplasia, possibly by activation of protooncogenes or inactivation of tumour suppressor genes. DNA adducts, however, are considered a necessary, but not the only, event in carcinogenesis. ${ }^{10}$

At the level of the target tissue, measurements are made of the biologically effective dose-for example, aryl carcinogen-DNA adducts measured in peripheral lung tissue. ${ }^{12}$ Measurements can also be made in surrogate tissues - for example, PAH-DNA adducts in white blood cells. ${ }^{13}$ The extrapolation of markers in surrogate tissue to actual risk of disease in specific target organs must, however, be interpreted with caution. Furthermore, many of the biomarkers currently being examined may reflect recent, but not cumulative exposure.

DNA adducts resulting from many potential carcinogens can be measured with various techniques, such as ${ }^{32} \mathrm{P}$ postlabelling or gas chromatography-mass spectrometry. These in- clude arylamines, nitrosamines, PAHs, heterocyclic amines, aflatoxin B1 (AFB1), ${ }^{14}$ chlorinated pesticides, ${ }^{15}$ and some herbicides. ${ }^{16}$

\section{Markers of early biological response}

Markers of early biological effects include mutations and cytogenetic damage. They are used as surrogate end points to predict risk of disease. Examples of such markers are oncogenes and tumour suppressor genes, or their products.

\section{ONCOGENES}

Oncogenes encode proteins that are involved in regulation of normal cellular growth and division. Various environmental agents can alter these genes and promote abnormal cell proliferation. An example of an oncogene is the ras oncogene that encodes proteins, associated with membranes, which relay growth factors and other cellular proteins to interact with receptors. Environmental agents such as PAHs and AFB1 can cause point mutations and "activate" the ras gene.

Activated ras genes are found not only in cancerous, but also in premalignant tissues. The ras gene, or its protein product, can thus be a useful biomarker in identifying early oncogenic processes at the premalignant stage.

Studies of molecular biomarkers of oncogene proteins such as ras oncogene encoded p21 protein $^{17}$ and Asp13-Ki-ras oncoprotein ${ }^{18}$ have been conducted among occupational groups - namely, foundry workers,${ }^{19}$ hazardous waste workers, ${ }^{20}$ firefighters, ${ }^{21}$ and workers exposed to vinyl chloride monomer. ${ }^{18}$

\section{p53}

The p53 tumour suppressor gene is located on the short arm of the human chromosome 17. It consists of 11 exons spanning $20 \mathrm{~kb}$ DNA and encodes a $53 \mathrm{kDa}$ nuclear protein. ${ }^{22}{ }^{23}$ Mutations in p53 are found in about $50 \%$ of tumours. There have been several p53 studies conducted in occupational groups. Among workers exposed to vinyl chloride, it was reported that the presence of p53 mutant protein showed a dose-response relation. ${ }^{24}$ Besides p53 mutation rate being expressed as a dichotomous event, specific p53 mutation 
characteristics have been studied. These are thought to reflect aetiological contributions of environmental or endogenous factors.

For example, p53 mutations in lung cancer are different in workers exposed to radon compared with non-exposed populations. ${ }^{25}$ In the case of liver cancer, transversions of the DNA bases $\mathrm{G}: \mathrm{C}$ to $\mathrm{T}: \mathrm{A}$ in $p 53$ were noted in 30\% to $50 \%$ of tumours in high incidence areas where there was intake of AFB1. These transversions clustered at "hotspots" such at codon 249. Such mutations were not commonly noted in areas with little exposure to AFB $1{ }^{26}$ The mutagenic specificity is likely to be due to dietary exposure to AFB1. The same mutation is seen during in vitro experiments with $\mathrm{AFB} 1 .{ }^{27}$

\section{Markers of host susceptibility}

Examples of host susceptibility to occupational diseases are already known to OEM physicians - for example, deficiency in glucose6-phosphate dehydrogenase (G6PD) and risk of haemolysis when exposed to oxidising chemicals - such as naphthalene-and $\alpha_{1-}$ antitrypsin deficiency and increased sensitivity on exposure to respiratory irritants.

Genes affecting the metabolic ability of the person, or markers of those genes, have been used to study host characteristics that modify the effect of exposure to environmental agents and to identify high risk or genetically susceptible people. Occupational diseases where individual susceptibility may be important include various occupational cancers and cytochrome $P-450$ and acetylator state.

CYTOCHROME $P$-4501A1 ENZYME

Cytochrome P-4501A1 (CYP1A1) is a membrane bound phase I biotransformation enzyme. ${ }^{28}$ It contains two closely linked polymorphisms that have been associated with increased risk of lung cancer. ${ }^{29}$ One is a restriction fragment length polymorphism downstream from the coding region $\mathrm{Mspl}$, the other a point mutation in exon 7 that substitutes valine for isoleucine in the protein. ${ }^{30}$

Benzo(a)pyrene $(\mathrm{BaP})$ is metabolised by cytochrome $P-450$ monoxygenase system. Thus, environmentally exposed people with an increased CYP1A1 enzyme activity will produce more reactive metabolites of $\mathrm{BaP}$. One reactive metabolite is 7,8-dihydrodiol-9,10epoxide (BPDE), which can react with DNA to form a covalently bound adduct. This further undergoes conjugation with glutathione through glutathione S-transferase (GST) or detoxification by another phase II enzyme system.

GLUTATHIONE TRANSFERSE (GST)

Deletions of GSTM1, a non-inducible phase II cytosolic detoxification enzyme that catalyses conjugation of reactive electrophiles to reduced glutathione, is also associated with increase risk of cancer. GSTP1, which is usually expressed in the blood brain barrier, may influence response to neurotoxins and thus explain the susceptibility of some people to the effects of pesticides that induce parkinsonism. ${ }^{31}$
N-ACETYL TRANSFERASE ACETYLATOR STATE $\mathrm{N}$-acetyl transferase (NAT) acetylator is a modulator of risk of bladder cancer induced by arylamines. Gene variants of NAT2 result in different rates of biotransformation of carcinogens - for example, arylamine and hydrazine. In the case of bladder cancer, $\mathrm{N}$-acetylation of arylamines-such as 4-aminobiphenyl (ABP) - is a competing pathway for N-oxidation, where NAT2 behaves as a detoxifier. ${ }^{32}$ Thus an increased risk of bladder cancer is found among phenotypically slow acetylators. ${ }^{33} \mathrm{~A}$ meta-analysis ${ }^{34}$ with combined data from 12 studies found an RR of 1.5 (95\% confidence interval ( $95 \%$ CI) 1.2 to 1.7 ) in slow compared with rapid acetylators.

\section{DNA REPAIR GENES}

The primary role of these genes is to maintain the integrity of the genome by removing lesions, such as $\mathrm{O}^{6}$-methylguanine $\left(\mathrm{O}^{6}\right.$-meg), which are created by chemical and other environmental exposures. Unrepaired lesions contribute to cell death, mutation, chromosome damage, and carcinogenesis.

Examples of human DNA repair genes include the $\mathrm{O}^{6}$-methylguanine DNA methyltransferase (MGMT) gene, and the 3-methyladenine DNA glycosylase (MAG) gene involved in excision repair of methylated adenine residues and other lesions-for example, N6ethenoadenine (epsilon A). ${ }^{32}$

However, comparatively few studies have been made on the effect of DNA repair genes in environmentally exposed populations.

RESEARCH ON RECEPTOR SITES

Another application of molecular biology is the study of receptor interactions. Aberrant receptors (which may result from environmental exposure) would compete with normal receptors for binding to the responsive DNA and interfere with the normal transcription control mechanism. The methods are still at the research level and currently not suitable for human monitoring. ${ }^{35}$

\section{Application of new technology in biomarker studies: issues to consider} By examining markers at each step of a hypothesised aetiological pathway, the intervening process can be studied and the interactions between them better understood. This is essential for a coherent picture to emerge, as has been shown by the study of aflatoxin as a human hepatic carcinogen (reviewed by Groopman and Kensler ${ }^{6}$ ) and in the pathogenesis of bladder cancer induced by arylamine. ${ }^{36}$ It is also a prerequisite for the meaningful design and interpretation of epidemiological studies that use these markers.

VALIDATION OF THE BIOMARKER

A major challenge that is continually being considered is the question of validation. To be useful, an exposure marker must be shown to accurately (in terms of presence and magnitude) reflect past exposure to the agent, and a risk marker should accurately reflect risk of disease. ${ }^{6}$ There are many factors to be 
considered, among which are properties of the biomarker itself, its lifespan and hence the period of exposure reflected, and its stability during collection and processing. ${ }^{37}$

VARIABILITY WITHIN PEOPLE

The importance of understanding variability within people cannot be overemphasised. This variability may be a function of the timing of sample collection, or the sampling procedure itself. This is shown in a study ${ }^{38}$ which found that $80 \%$ of variation in colonic mucosal proliferation indices is due to biopsy within the subject-for example, the site of samplingand crypts within the biopsy. Other sources of variability within a person could arise from errors in handling, processing, and storing of specimens. ${ }^{39}$

VARIATION IN INSTRUMENTAL ANALYSIS

Furthermore, different analytical methods are available for measurement of molecular biomarkers. As an example, for the analysis of adducts, chromatography, immunoassays, and other methods based on instruments are some of the methods used. These methods have different sensitivity and specificity, and may show batch to batch variation. In a human study on aflatoxin, ${ }^{6}$ it was reported that inherent day to day variation in the assay method contributed to the poor tracking of how well a subject's biomarker remained positioned in a rank order (relative to others in the group) over time.

Quality control in the laboratory is important. It should be applied to complex analysis of cell based biomarkers-for example, hypoxanthine phosphoribosyl transferase (HPRT) mutation and adduct analysis ${ }^{40}$ - even though such quality control is more difficult to incorporate. Furthermore, many of these molecular biomarkers are fairly recently developed. High coefficients of variation can be expected in the early stages of development, and reflect the wide range of conditions used at each stage in the different laboratories. ${ }^{40}$

CORRELATION WITH OTHER MEASURES

A valid exposure marker should correlate well with other related measures, as in the case of urinary 1-hydroxypyrene, commonly used as a marker of exposure to PAHs. Studies have shown strong correlations between 1-hydroxypyrene concentrations after a work shift and concentrations of dermal and breathing zone pyrene or benz(a)pyrene. The marker was also sensitive to changes in levels of exposure. ${ }^{1141} \mathrm{~A}$ good correlation has also been found with hours of working in a foundry and concentrations of PAH-DNA adducts after adjusting for smoking and consumption of broiled food. ${ }^{42}$

CONFOUNDING AND BIAS

A further methodological consideration is the identification of appropriate confounders that may give rise to spurious relations if the potential interaction over various metabolic pathways and routes of exposure are not taken into account. Confounding as a statistical phenomenon can be related to different biological processes. Induction of metabolic enzymes by concurrent exposures, competing metabolic pathways or exposure through nonoccupational sources that have not been accounted for, are some examples.

In occupational settings, detection bias due to a more careful follow up of high risk people may pose problems of interpretation. This may occur during surveillance of workers exposed to chemical hazards - for example, if the process of follow up, or the measurement of exposure itself leads to the disease (or other end point) being more likely to be detected in the exposed group. ${ }^{43}$

The healthy worker effect, a form of selection bias, may occur if genetic determinants of good health in general are also part of the pathway of the exposure under study. For example, genetic variation in dopamine receptor (DRD1) activity has been linked to smoking, alcohol use, gambling, and other addictive behaviours. ${ }^{44}{ }^{45}$ Studies in an occupational setting that use markers which involve central neural dopaminergic pathways should take into account the possibility that the working population would have a different profile from the general population due to selection factors.

Finally, many of the studies on molecular biomarkers have relatively low power, as the number of subjects and the increase in health risk for low level exposures in these studies are generally small.

\section{ETHICAL ISSUES}

As potential end users of the new technology, OEM practitioners should also consider critically the impact of these advances on practice. The assessment should be made not only on scientific, but also on ethical and social grounds. For example, should genetic tests be used to identify susceptible workers? This raises issues of individual privacy, labelling, denial of insurance or employment, and other possibly unanticipated harms. Calls have been made for debate on social norms and legislation to protect people in advance of the application of such tools in evaluating risk. ${ }^{46} \mathrm{~A}$ pertinent question to ask is whether the test is undertaken to benefit the person or to fulfil some administrative or financial need. ${ }^{47}$

\section{The future}

The use of biomarkers in OEM is not a new phenomenon, but one that is well established. Advances in molecular medicine and molecular epidemiology, however, offer new tools for OEM practitioners. Practitioners should refrain from being dazzled by these tools because they are new and fashionable, but rather critically evaluate their use and consider their implications on practice.

What is apparent is that the understanding of biochemistry and genetics at the molecular level and specific knowledge on metabolism and mechanisms of action have become increasingly important for the OEM practitioner. Some exposure to, or education in, these disciplines is needed, as well as the existing training in epidemiology, occupational 
hygiene, toxicology, and environmental and occupational medicine.

Although most of the techniques of molecular epidemiology are still in the research stage, these may be applied in the field in the future. Meanwhile, validation of the results with complementary experimental animal and human studies is needed.

Currently, most of the tools available for predicting individual risk are still rather imprecise and not sufficiently refined. Given the limitations of individual molecular biomarkers in assessing individual disease risk, and the multifactorial nature of cancers and chronic disease, it is likely that combinations of markers (internal dose, adduct, metabolic phenotype, DNA repair ability) are needed to assess risk. Groopman and Kensler ${ }^{6}$ stated that: "Thus most validated risk markers may turn out to be composites of a group of biomarkers, each of which contributes in some quantifiable way to overall risk. Assembling and validating this collection of biomarkers will be a major challenge."

Several studies ${ }^{42} 4849$ have presented data on environmental measurements and composites of biomarkers (for internal dose, biologically effective dose, genetic polymorphisms, early response markers). Such studies will increase our understanding of the complex issue of disease mechanisms and further refine the process of individual risk assessment.

1 Perera FP, Weinstein IB. Molecular epidemiology and carcinogen-DNA adduct detection: new approaches to studies of human cancer causation. $f$ Chron Dis 1982;35:581-600

2 Hulka BS. Overview of biological markers. In: Hulka BS, Wilcosky TC, Griffith JE, eds. Biological markers in epidemiology. New York: Oxford Univ Press, 1990:3-15.

3 Perera F, Santella R, Piorier M. Biomonitoring of workers exposed to carcinogens: immunoassays to benzo(a)pyreneDNA

4 Schulte PA. Contribution of biological markers to occupational health. Am f Ind Med 1991;20:435-46.

5 McMichael AJ. Invited commentary: molecular epidemiology: new pathway or new travelling companion? Am ₹ Epidemiol 1994;140:1-11

6 Groopman JD, Kensler TW. The light at the end of the tunnel for chemical-specific biomarkers: daylight or headlight? Carcinogenesis. 1999;20:1-11.

7 Soderkvist P, Axelson O. On the use of molecular biology data in occupational and environmental epidemiology. $\mathcal{F}$ Occup Environ Med 1995;37:84-90.

8 Samet JM, Schnatter R, Gibb H. Epidemiology and risk assessment. Am f Epidemiol 1998;10:929-36.

9 Perera F. Uncovering new clues to cancer risk. Sci Am 1996; 275:40-6.

10 Perera FP; Dickey C. Molecular epidemiology and occupational health. Ann N Y Acad Sci 1997;837:353-9.

11 Kuljukka T, Vaaranrinta R, Mutanen P, et al. Assessment of occupational exposure to PAHs in an Estonian coke oven plant: correlation of total external exposure to internal dose measured as 1-hydroxypyrene concentration. Biomarker 1997;2:87-94.

12 Wilson VL, Weston A, Manchester DK, et al. Alkyl and aryl carcinogen adducts detected in human peripheral lung. Carcinogenesis 1989;10:2149-53.

13 Santella R, Hemminki K, Tang D, et al. PAH-DNA adducts in white blood cells and urinary 1-hydroxypyrene in foundry workers. Cancer Epidemiol Biomarkers Prev 1993;2:5962.

14 Shi CY, Seow A, Lin Y, et al. Biomarkers: a molecular approach to cancer epidemiology. Ann Acad Med Singapore 1996;25:49-54.

15 Dubois M, Grosse Y, Thome JP, et al. Metabolic activation and DNA-adducts detection as biomarkers of chlorinated pesticide exposures. Biomarkers 1997;2:17-24.

16 McClure GYH, Freeman JP, Lay JO, et al. Haemoglobin adducts as biomarkers of exposure to the herbicides propanil and fluometuron. Biomarkers 1996;1:136-40.

17 Brandt-Rauf PW. Oncogene proteins as biomarkers in the molecular epidemiology of occupational carcinogenesis. The example of the ras oncogene-encoded $\mathrm{p} 21$ protein. In Arch Occup Environ Health 1991;63:1-8.

18 Luo JCJ, Lu HT, Cheng TJ, et al. Plasma Asp13-Ki-ras oncoprotein expression in vinyl chloride monomer workers in Taiwan. F Occup Environ Med 1998;40:1053-8.
19 Brandt-Rauf PW, Smotj S, Perera FP, et al. Serum oncogene proteins in foundry workers. Fournal of the Society of Occupational Medicine 1990;40:11-4.

20 Brandt-Rauf PW, Smith S, Niman HL, et al. Serum oncogene proteins in hazardous waste workers. $\mathcal{F}$ Soc Occup Med 1989;39:141-3.

21 Ford J, Smith S, Luo JC, et al. Serum growth factors and oncoproteins in firefighters. Occup Med 1992;42:39-42.

22 Harris CC. p53: At the crossroads of molecular carcinogenesis and risk assessment. Science 1993;262:1980-1.

23 Esteve A, Sorlie T, Martel-Planche G, et al. Screening for p53 gene mutations in archived tumors of workers occupationally exposed to carcinogens: examples from analysis of tionally exposed to carcinogens: examples from analy

24 Smith SJ, Li YL, Whitley R, et al. Molecular epidemiology of p53 protein mutations in workers exposed to vinyl chloride. Am $\mathcal{F}$ Epidemiol 1998;147:302-8.

25 Husgafvel-Pursiainen K, Ridanpaa M, Anttila S, et al. p53 And ras gene mutations in lung cancer: implications for smoking and occupational exposures. F Occup Environ Med 1995;37:69-76.

26 Shi CY, Phang TW, Lin Y, et al. Codon 249 mutation of the p53 gene is a rare event in hepatocellular carcinomas from ethnic Chinese in Singapore. Br F Cancer 1995;72:146-9.

27 Shen HM, Ong CN. Mutations of the p53 tumor suppressor gene and ras oncogenes in aflatoxin hepatocarcinogenesis. Mutat Res 1996;366:23-44.

28 Rannug A, Alexandrie AK, Persson I, et al. Genetic polymorphism of cytochromes P450 1A1, 2D6 and 2E1: regulation and toxicological significance. $\mathcal{F}$ Occup Environ Med 1995;37:25-36

29 Garte S. The role of ethnicity in cancer susceptibility gene polymorphisms: the example of CYP1A1. Carcinogenesis 1998;19:1329-32.

30 Hayashi S, Watanabe J, Kawahri K. High susceptibility to lung cancer analysed in terms of combined genotype of P4501A1 and Mu-class glutathione S-transferase genes. fpn $\mathcal{F}$ Cancer Res 1992;83:866-70.

31 Menegon A, Board PG, Blackburn AC, et al. Parkison's disease, pesticides, and glutathione transferase polymorphisms. Lancet 1998;352:1344-6.

32 Ishibe N, Kelsey KT. Genetic susceptibility to environmental and occupational cancers. Cancer Causes Control 1997;8: $504-13$

33 Yu MC, Skipper PL, Taghizadeh K, et al. Acetylator phenotype, aminophenyl-haemoglobin adduct levels, and bladder cancer risk in whites, black and Asian men in Los Angeles. f Natl Cancer Inst 1994;86:712-6.

34 Hein DW. Acetylator genotype and arylamine-induced carcinogenesis. Biochim Biophys Acta 1988;948:37-66.

35 Vainio H. Molecular approaches in toxicology: change in perspective. F Occup Environ Med 1995;37:14-8.

36 Ross RK, Jones PA, Yu MC. Bladder cancer epidemiology and pathogenesis. Seminars in Oncology 1996;23:536-45.

37 Chia KS, Shi CY, Lee J, et al. Molecular epidemiology: issues in study design and statistical analysis. Ann Acad Med Singapore 1996 25:55-63.

38 Lyles CM, Sandler RS, Keku TO, et al. Reproducibility and variability of the rectal mucosal proliferation index using proliferating cell nuclear antigen immunohistochemistry. Cancer Epidemiol Biomarkers Prev 1994;3:51-6.

39 Vineis P. Sources of variation in biomarkers.In: Toniolo P, Boffetta P, Shuker DEG, et al, eds. Application of biomarkers in cancer epidemiology. Lyon: International Agency for
Research on Cancer, 1997:59-71. (IARC Sci Publ No 142.)

40 Gompertz D. Quality control of biomarker measurement in epidemiology. In: Toniolo P, Boffetta P, Shuker DEG, et al, eds. Application of biomarkers in cancer epidemiology. Lyon: International Agency for Research on Cancer, 1997:21522. (IARC Sci Publ No 142.)

41 VanRooij JGM, Bodelier-Bade MM, Jongeneelen FJ. Estimation of individual dermal and respiratory uptake of polycyclic aromatic hydrocarbons in 12 coke oven workers. Br F Ind Med 1993;50:623-32.

42 Hemminki K, Dickey C, Karlsson S, et al. Aromatic DNA adducts in foundry workers in relation to exposure, lifestyle and CYP1A1 and glutathione transferase M1 genotype. Carcinogenesis 1997; 18:345-50.

43 Vineis P, McMichael AJ. Bias and confounding in molecular epidemiological studies: special considerations. Carcinogenesis 1998;19:2063-7.

44 Comings DE, Gade R, Wu S, et al. Studies of the potential role of the dopamine D1 receptor gene in addictive behaviours. Mol Psychiatry 1997;2:44-56.

45 Shields PG, Lerman C, Audrain J, et al. Dopamine D4 receptors and the risk of cigarette smoking in AfricanAmericans and Caucasians. Cancer Epidemiol Biomarkers Prev 1998;7:453-8.

46 Barrett JC, Vainio H, Peakall D, et al. 12th Meeting of the Scientific Group on Methodologies for the Safety Evaluation of Chemicals: susceptibility to environmental hazards. Environ Health Perspect 1997;105:699-737.

47 Koh D, Jeyaratnam J. Biomarkers, screening, and ethics. Occup Med (Oxf) 1998;48:27-30.

48 Pan G, Hanaoka T, Yamano Y, et al. A study of multiple biomarkers in coke oven workers: a cross-sectional study in China. Carcinogenesis 1998;19:1963-8.

49 Peluso M, Airoldi L, Armelle M, et al. White blood cell DNA adducts, smoking, and NAT2 and GSTM1 genotypes in bladder cancer: a case-control study. Cancer Epidemiol Biomarkers Prev 1998; 7:341-6. 